\title{
Determination of Effective Electron Source Position for Beam Shaper Applicator in Intraoperative Radiotherapy
}

\author{
Nematollah Heidarloo ${ }^{1}$, Hamid Reza Baghani ${ }^{2}$, Seyed Mahmoud Reza Aghamiri ${ }^{3}$
}

1. Ph.D. Candidate, Department of Medical Radiation Engineering, Faculty of Nuclear Engineering, Shahid Beheshti University, Tehran, Iran. ORCID ID: 0000-0003-0091-0357

2. Assistant Professor, Physics Department, Faculty of Science, Hakim Sabzevari University, Sabzevar, Iran., (Corresponding Author), Tel: +98-51-44013216, Email: h.baghani@ hsu.ac.ir, ORCID ID: 0000-0003-0392-9192

3. Professor, Department of Medical Radiation Engineering, Faculty of Nuclear Engineering, Shahid Beheshti University,Tehran, Iran. ORCID ID: 0000-0002-5080-0482

\begin{abstract}
Background and Aim: Beam shaper applicator is one of the dedicated applicators for intraoperative electron radiotherapy which is usually employed for large tumors irradiation. Due to the high weight and lack of possibility of direct placement on the patient's body, a considerable air gap exists between the applicator and patient. Therefore, determination of the effective position of electron source ( $\mathrm{SSD}_{\text {eff }}$ ) is absolutely necessary to correct the applicator output for air gap effect and accurate delivery of the prescribed dose to the patient. The aim of this study was to determine the $\mathrm{SSD}_{\text {eff }}$ for all square fields of beam shaper applicator at different electron energies using Monte Carlo (MC) simulation.
\end{abstract}

Materials and Methods: At first, the head of LIAC accelerator and beam shaper applicator were simulated by MCNPX MC code and then, the validity of the simulated model was evaluated through comparing the calculated percentage depth dose (PDD) curves at different field sizes and energies with the corresponding practiacal values. After verifying the simulated model, the $\mathrm{SSD}_{\text {eff }}$ was determined for different field sizes and electron energies using inverse square law (ISL) method.

Results: The results showed that the $\mathrm{SSD}_{\text {eff }}$ is a function of electron energy and radiation field size. Dependency of $\mathrm{SSD}_{\text {eff }}$ on field size variations was much more than that on the alterations in the electron energy. Generally, increase in the field size or electron energy led to increase in $\mathrm{SSD}_{\text {eff. }}$.

Conclusion: The determined $\mathrm{SSD}_{\text {eff }}$ values for the electron beam of the beam shaper applicator in our study, can be used to correct the electron beam output for clinical purposes.

Keywords: Effective position of electron source ( $\mathrm{SSD}_{\text {eff }}$ ), Intraoperative radiotherapy, Beam shaper applicator, Monte Carlo simulation, LIAC dedicated accelarator

Received: Feb 24, 2019

Accepted: April 17, 2021

How to cite the article: Nematollah Heidarloo, Hamid Reza Baghani, Seyed Mahmoud Reza Aghamiri. Determination of effective electron source position for beam shaper applicator in intraoperative radiotherapy.SJKU 2021;26(4):80-92.

Copyright (C) 2018 the Author (s). Published by Kurdistan University of Medical Sciences. This is an open access article distributed under the terms of the Creative Commons Attribution-Non Commercial License 4.0 (CCBYNC), where it is permissible to download, share, remix, transform, and buildup the work provided it is properly cited. The work cannot be used commercially without permission from the journal 


\section{تعيين موقعيت مؤثر جشمه الكترون براى إيليكاتور Beam shaper در يرتودر مانى حين عمل \\ نعمتاله حيدرلو'، حميد رضا باغانى '، سيد محمود رضا آقاميرى

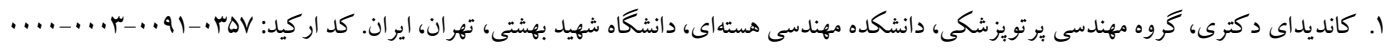

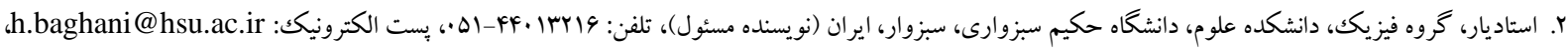
كد اركيد:

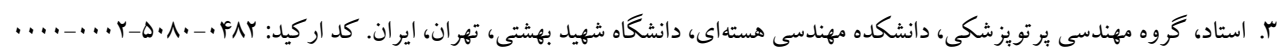

جكيuه

زمينه و هدف: إِيلكاتور Beam shaper يكى از إيليكاتورهاى اختصاصى مورد استفاده در برتودرمانى حين عمل توسط باريكه

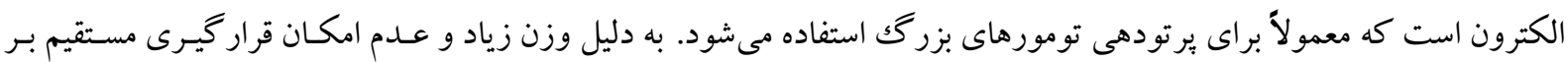

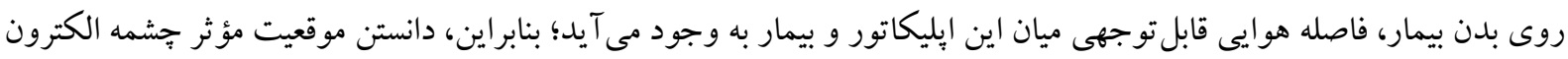

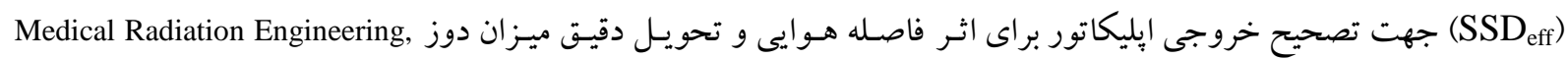
Faculty of Nuclear Engineering, Shahid Beheshti University,Tehran, IranMedical Radiation Engineering, Faculty of Nuclear

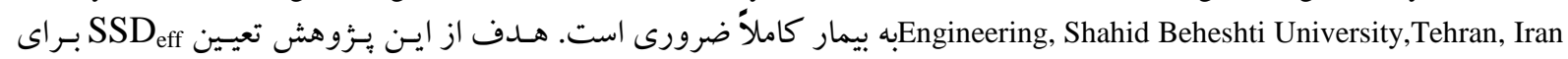

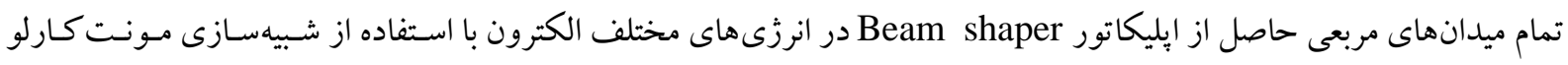

مواد و روشها: ابتدا سر شتابدهنده LIAC به همراه إيليكاتور Beam shaper توسط كـد مونـت كـارلوى MCNPX شبيه -

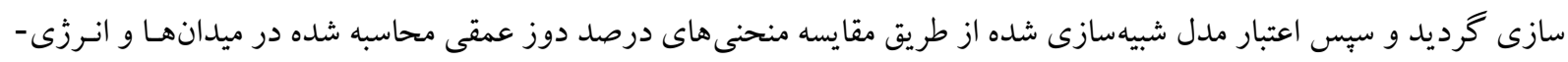

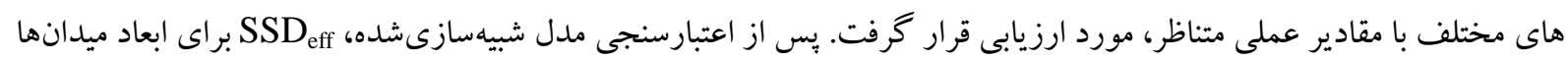

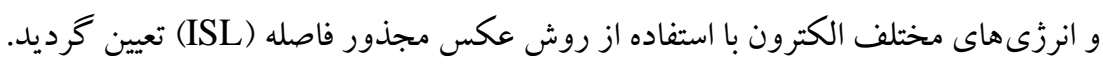

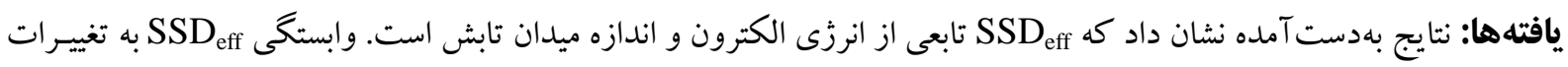

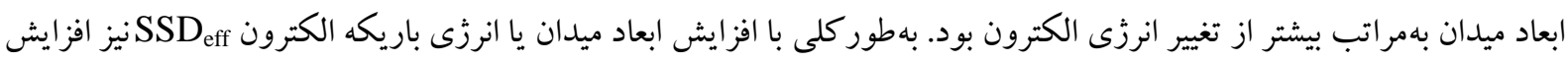
مى يابد. نتيجه كيرى: مقادير SSD تعيين شده براى باريكه الكترون إيليكاتور Beam shaper در مطالعه حاضر، مى تواند جهـت اصـلاح خروجى باريكه الكترون در مقاصد بالينى به كار گرفته شود.

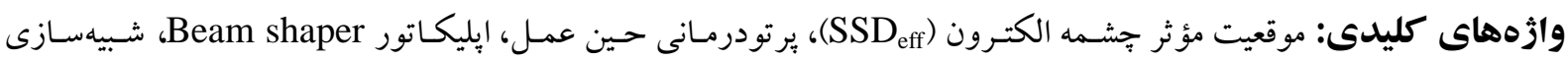
مونت كارلو، شتابدهنده اختصاصى LIAC وصول مقاله: وV/T/T/Q اصلاحيه نهايى:99/I//TV يذيرش: 
شتاب دهنده هاى متحر كك اختصاصى براى برتودرمانى حين

عمل در حال حاضر توجه زيادى را به خود معطوف نمـوده

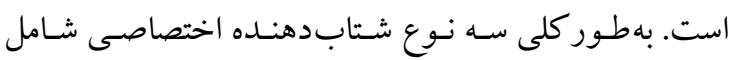
و NOVAC ، Mobetron

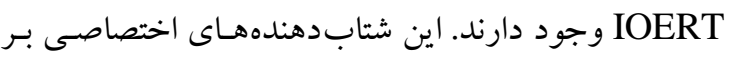

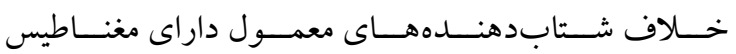

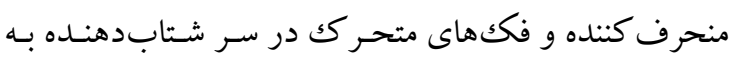
منظور انحر اف باريكه الكترون و شكل دادن به ميدان تـابش ونس

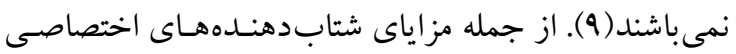
بر تودرمانى حين عمل در مقايسه با شتابدهندهواى معمـول

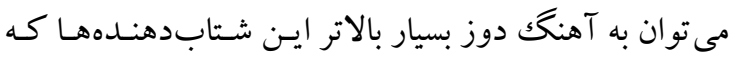

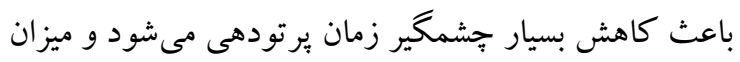

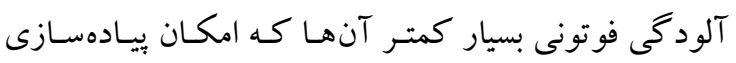

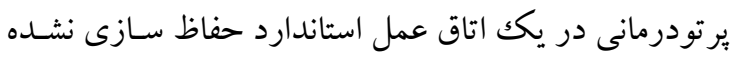

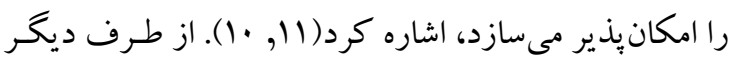

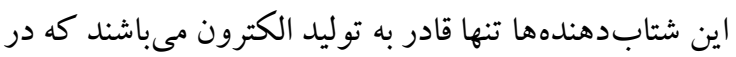
مقايسه با شتابدهندههاى معمول كه قادر به توليـد فوتـون و

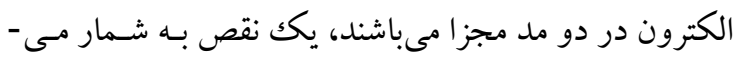

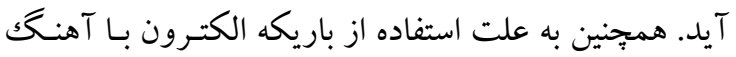

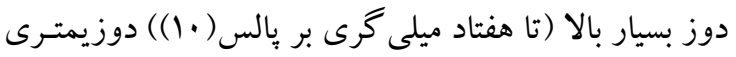
و كاليبراسيون اين شتابدهندهاى اختصاصى در مقايسه بـا شتابدهندهاى معمول كار مشكل و وييجيده ترى است(I I). موازىسازى باريكه الكترون در شتابدهندههاى برتودرمانى

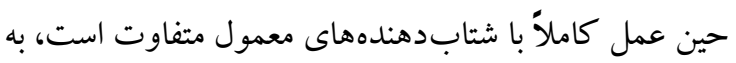

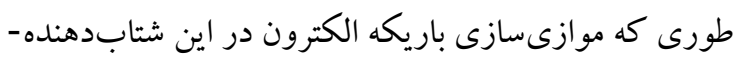

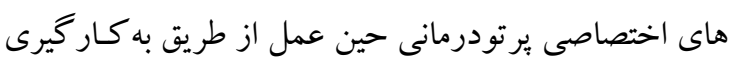
يكك سرى إيليكاتور طولى خاص با سطح مقطع هـاى دايره -

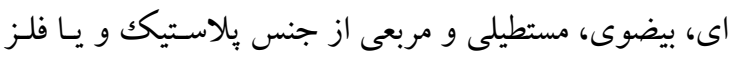
انجام مىشود(4 ، 1). مرسوم ترين إيليكاتورهاى مورد استفاده با شتابدهنـدهــاى برتودرمانى حين عمل إيليكاتورهـاى دايرهاى با حداكثر قطر ·ا سانتىمتر هستند. اين إيليكاتورهـا

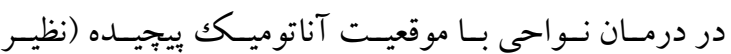

يرتودرمانى حين عمل (IORT) يكى از روش هـاى خـاص يرتودرمانى است كـه در طلى آن دوزهـاى بسيار بـالايى از

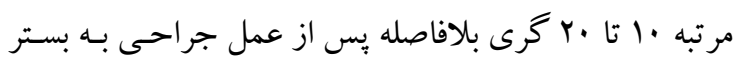
تومسور داده مسىشـود( (1). برتـودهى بـهـ بسـتر تومسور بعـد از

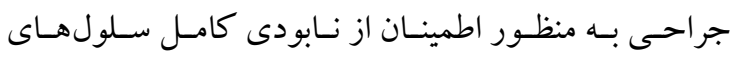

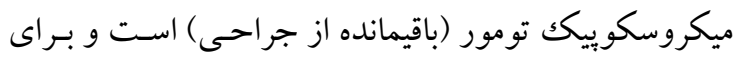

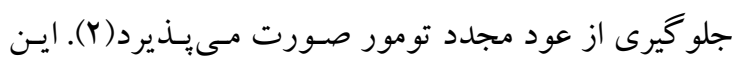
روش باسابقهاى با بيش از يكك قرن، ابتدا توسط متخصصان

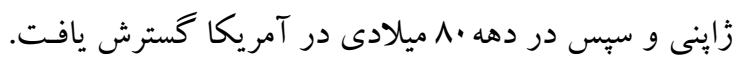
در حقيقـت بيشـينه IORT بـه تـلاشهـاى هوشـمندانه آبـه از زاين برمى گردد كه بعـدهـا توسط هو (Mitsuyuki Abe) يروفسور كـالوو (Felipe A Calvo) از اسِيانيا ادامـه يافتهـ

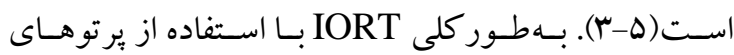

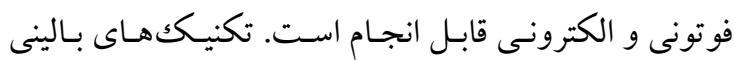

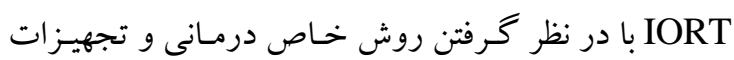

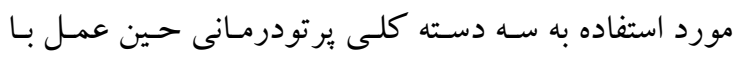
الكتـرون ( Intraoperative Electron Radiation HDR- و Low KV-IORT،(Therapy, IOERT IOERT تقسيمبنـدى مس شـود IO IO I) (1). در روش IORT يكك باريكه الكترونى براى برتودهى به بستر تومـور استفاده

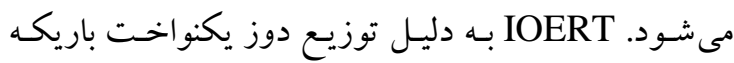

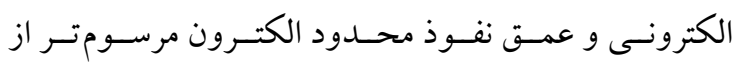
روشهاى ديخر است(^, V)؛ دوز حاصل از باريكه الكترون

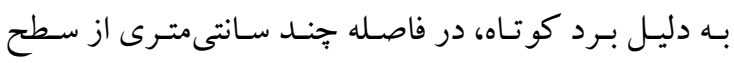
فرودى يرتو توزيع شده و به عمقهاى بيشتر بافت نفوذ ييـدا

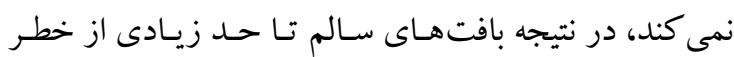

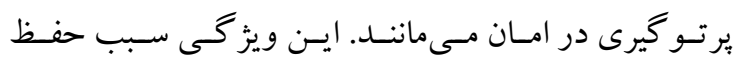

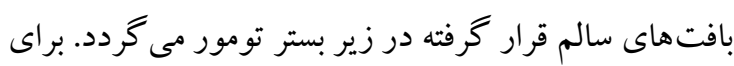

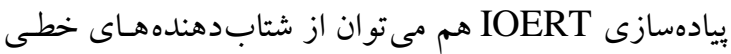

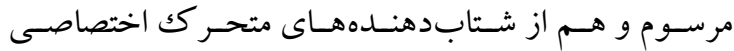
طراحىشده براى اين منظور استفاده كرد(r). استفاده از ايـن إسن 
بـراى ايـن اثرات اصـلاح نمـود (19, 1ه). بـرخلاف باريكه.

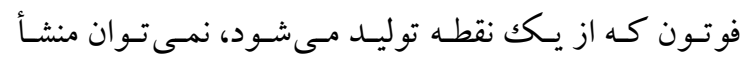

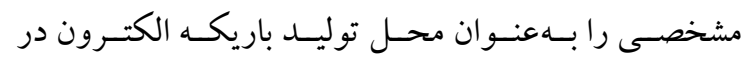
شتابدهندهاى خطى در نظر گرفـت. باريكه الكترون در

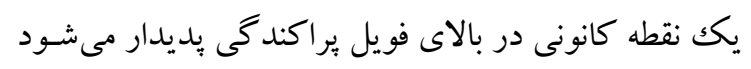

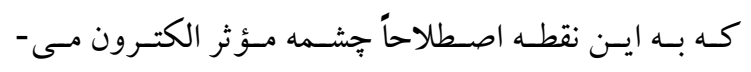

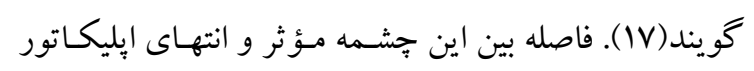

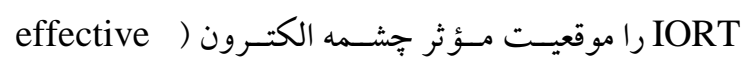
(source to surface distance, SSD مس $_{\text {eff }}$ يكك يارامتر مفيد براى اصلاح خروجى شتابدهنده بـا تغيير

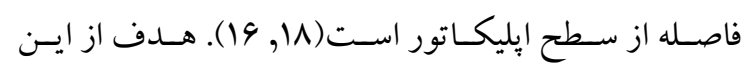

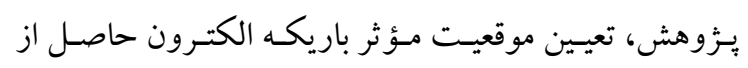

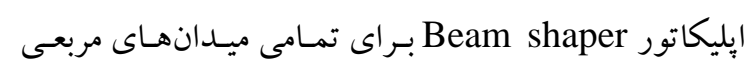
قابل توليد توسط اين ايليكاتور با استفاده از محاسبات مونت - كائل

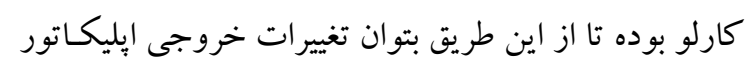
به دليل وجود فاصله هوا ميان سطح إيليكاتور و بدن بيمار را در طى برتودهى لحاظ نمود.

\section{مواد و روشها}

شتابدهنده اختصاصى :LIAC

شـتابدهنــده برتودرمـانى حسين عمـل LIAC داراى دو

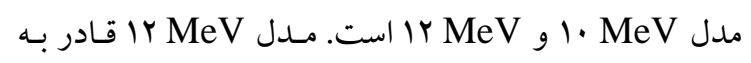

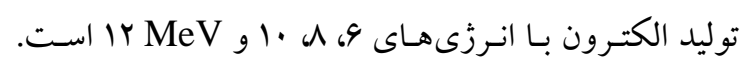

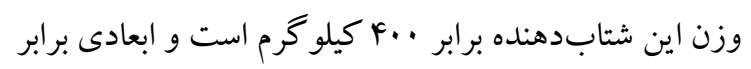

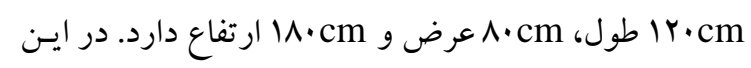
شتابدهنده هيج نوع مغناطيس منحرف كنــده بـراى باريكه.

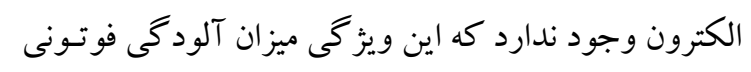

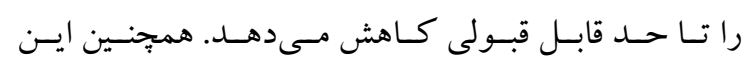

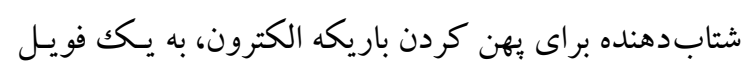

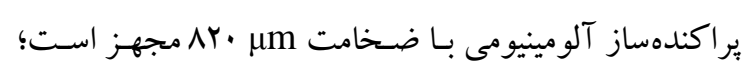

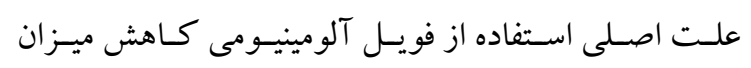
آلود كى فوتسونى و نـوترونى در انـرزىهـاى بـالا اسـت (19,
تومورهاى داخل شكم) با مشـكل مطابقـت انـدازه ميـدان بـا

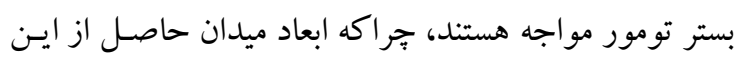

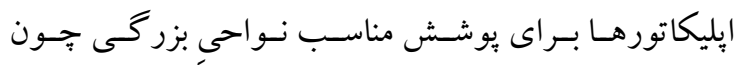
تومورهاى داخل شكم ناكافى است. بـراى رفع ايسن مشـكل

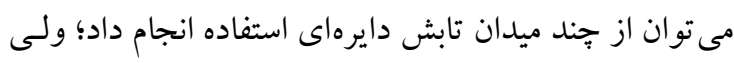

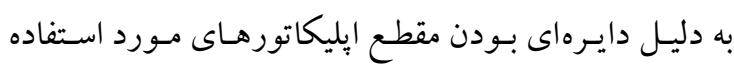
ممكن است در بخش هايى از بافتِ هدف هم يوشـانى ميـدان

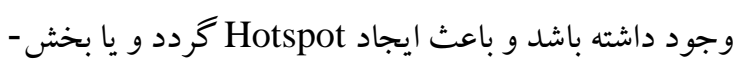

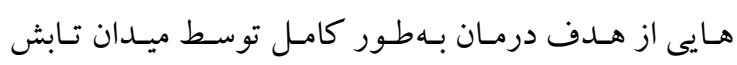

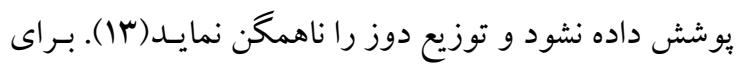

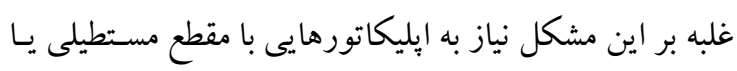

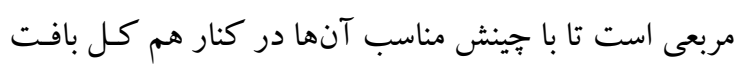

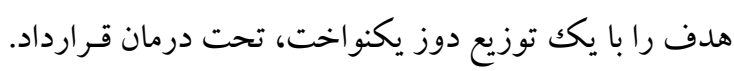

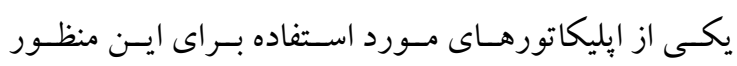

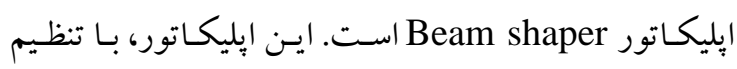
ييوسته شكل ميدان با استفاده از يكك سرى تيغه ضخيم قـادر

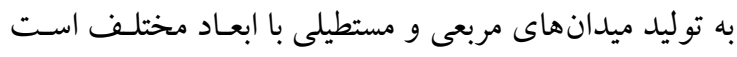

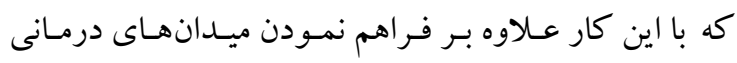

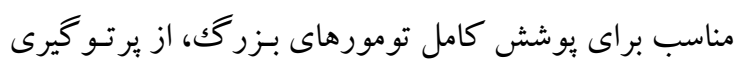

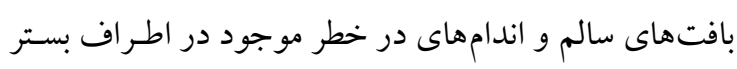
تومور، به دليل تضعيف مؤثر باريكه الكترون در داخل تيغه -

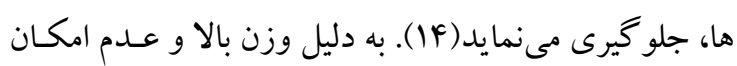

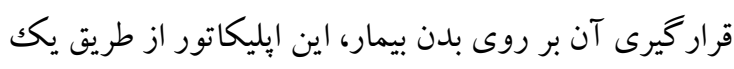

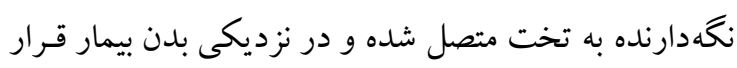

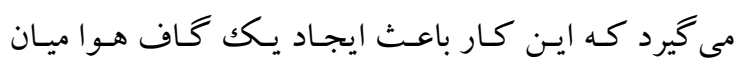

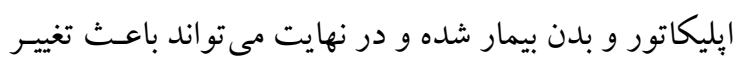

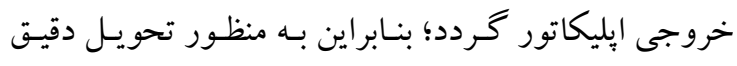

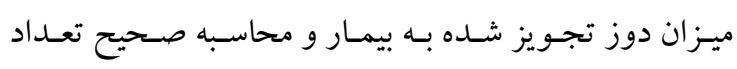

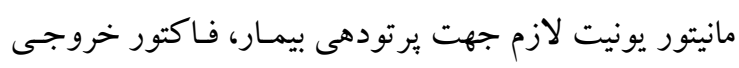

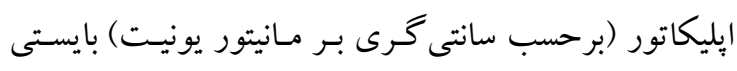

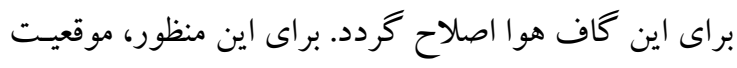

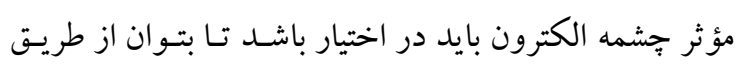
قانون عكس مجذور فاصله تغييـرات خروجى إيليكاتور را 
(تفلون) با ضخامت Y/9 cm و استيل زنگك نزن بـا ضخامت / c cm • ساخته شده است. لايه تفلونى كه داراى ضخامت بيشترى است، براى متوقـف كردن باريكه الكترون و لايـهـ استيل كه داراى ضخامت كمترى است، براى جـذب تـابش ترمزى ناشى از برهمكنش الكترون در تفلون مـورد استفاده

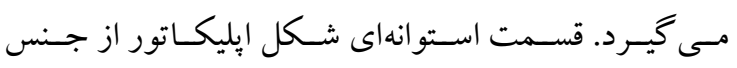
با ضخامت PMMA است. ابعاد اين إبليكاتور

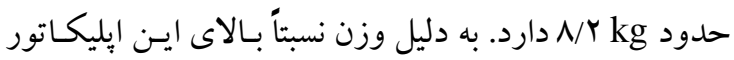

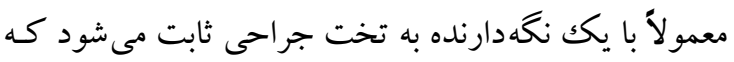

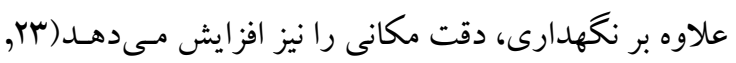

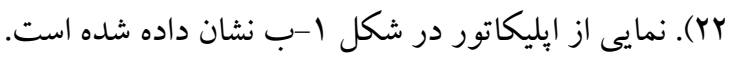

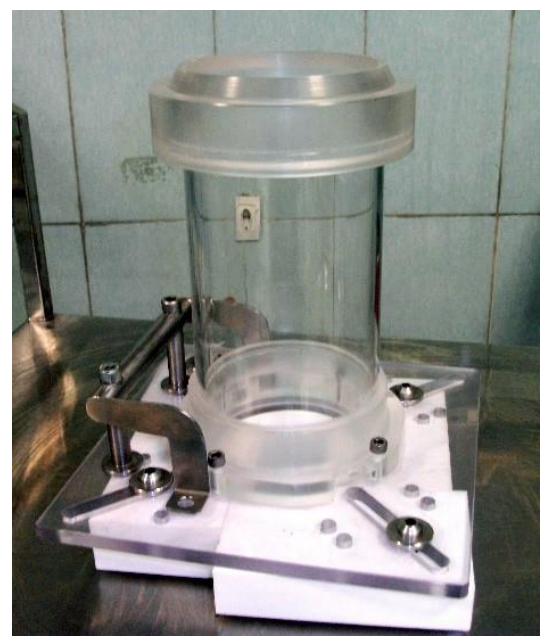

(ب)

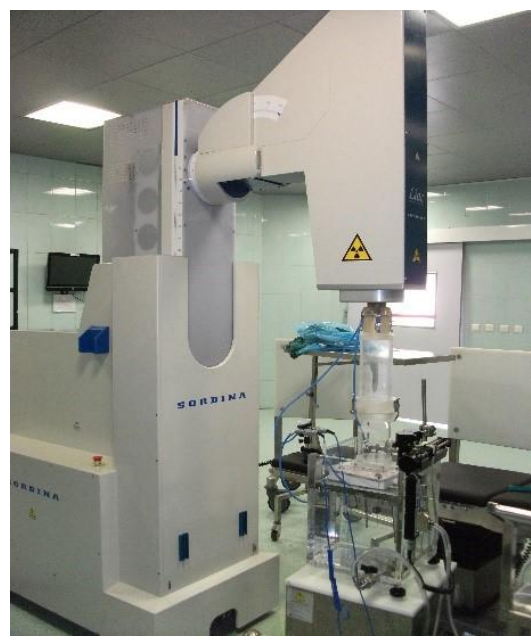

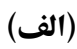

إيليكاتور Beam Shaper:

إيليكاتور Beam Shaper از جهار تيغه تشكيل شـده است كه دو به دو بهصورت كشويى باز و بسته مسى شود. حركت

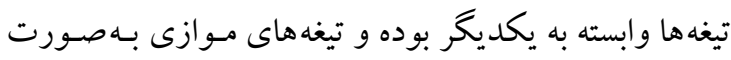
همزمان حركت مى كنند. اين تيغهها از دو لايه شامل PTFE

شكل ا. شتابدهنده LIAC موجود در بيمارستان خاتم الانبياء تهران همراه با إيليكاتور Beam shaper. (الف) در حال اندازه-

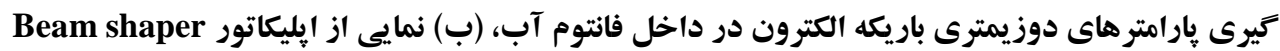
محاسبه موقعيت مؤثر جشمه الكترون:

(at Half Maximum, FWHM اشـاره كرد روشهـى. روش FWHM و FPC عمومـاً بـــاى انسـازه ميـدانهــاى بزرك تر از $10 \mathrm{MeV}$

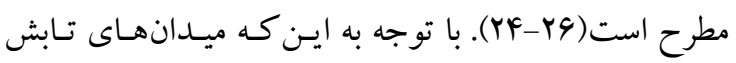

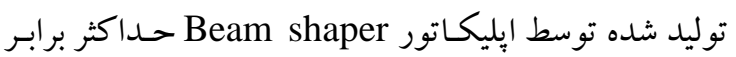

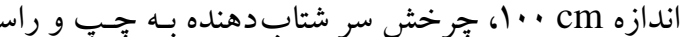
(roll angle) شتابدهنده در راستاى عرضى (pitch angle بازواياى به ترتيب •rو ها درجه از قابليت هاى ايـن سيستم اسـت (1) (Y. (Y). شكل 1 - الف نمايى كلى از اين شتابدهنده به همـراه با إيليكاتور Beam shaper در داخل فـانتوم آب ران انشـان مى دهل. . 
$\mathrm{SSD}_{\mathrm{eff}}=\frac{1}{\text { slope }}-z_{\text {max }}$

بنابر اين با تعيين مقادير ميان لبه إيليكاتور و سطح فانتوم و محاسبه شيبخط مربوطه، مى توان موقعيت مؤثر جشـمه (SSD

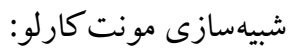

به منظور تعيين مقــادير دوز جـذبى بـه ازاى فواصـل هـوايى

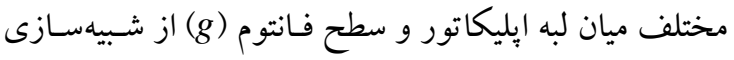
مونت كارلو استفاده شد. براى اين كار ابتدا سر شتابدهنده LIAC ${ }^{\mathrm{TM}}$ ويز گى هاى هندسى و فيزيكى كد مونت كارلوى MCNPX

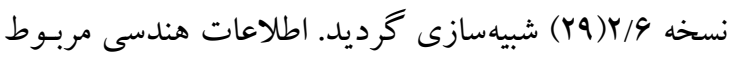
به سر شتابدهنده و إيليكاتور Beam shaper و همجنين اطلاعـات فيزيكى موردنيـاز شـامل طيـف انـرزى و توزيـع مكانى باريكه الكترون فرودى بر فويل بر اكندهساز، اندازهو

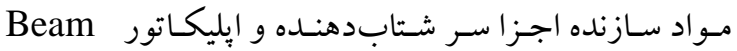
Shaper توسط شركت سازنده SORDINA، ايتاليا) تأمين

براى اعتبارسنجى مدل مونت كارلوى توسعه يافته و اطمينـان

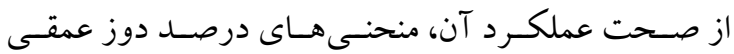
حاصل از شبيهسازى مونـت كـارلو بـا نتايج عملى (PDD)

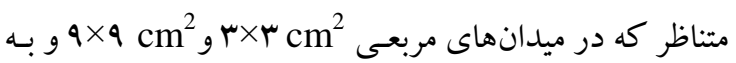

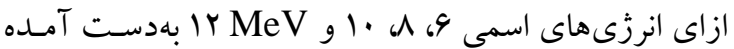
بودند، مقايسه گرديد. اين مقايسه بهصورت كمى و از طريق

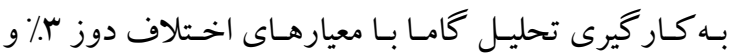
فاصله تا توافق mm rا، در مورد نتايج بهدست آمـده، انجـام كرفت و در نهايت مقادير شاخص كاما در عمقهاى مختلف

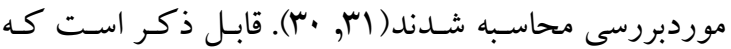
مقادير شاخص كامـاى كوجـكت تـر از يـك در بر آوردهـاى تحليل كاما به عنوان معيارى از وجود توافق ميـان نتـايج بـه دست آمده در نظر كرفته شد.
9 9 9 cm² 9 و حداكثر انرزى الكترون شتابدهنده اختصاصى نيز LIAC ${ }^{\mathrm{TM}}$ جشمه الكترون در اين كـار از روش عكس مجـذور فاصله استفاده شد. اين روش مبتنى بـر تعيـين دوز جـذبى در يـك الك

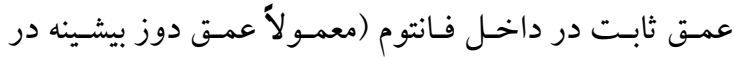

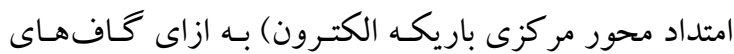

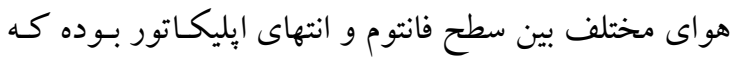

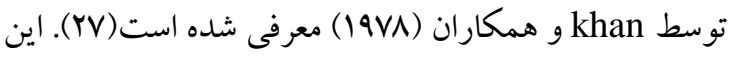
روش يكى از دقيقترين روشها براى تعيسين موقعيـت مـؤثر

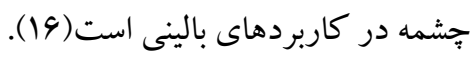
بر اساس اين روش، به ازاى فو اصل هوايى مختلف ميـان لبهـ

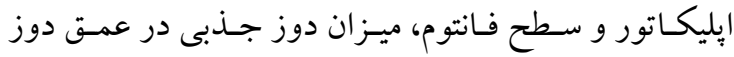

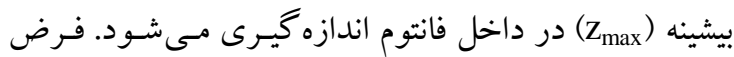
كنيد هوايى بين إيليكاتور و فانتوم (g=0) باشد و Ig دوز در همان

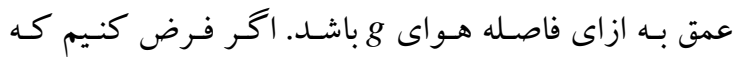

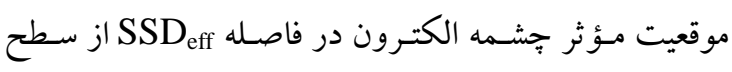

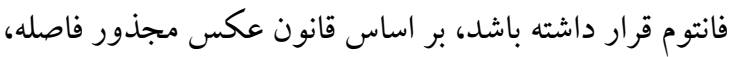

$$
\text { رابطه بين }
$$

$$
\begin{gathered}
\frac{I_{0}}{I_{\mathrm{g}}}=\left(\frac{\mathrm{SSD}_{\text {eff }}+z_{\max }+g}{\mathrm{SSD}_{\text {eff }}+z_{\max }}\right)^{2}, \\
\sqrt{\frac{I_{0}}{I_{\mathrm{g}}}}=1+\frac{g}{\mathrm{SSD}_{\text {eff }}+z_{\max }}
\end{gathered}
$$

مطابق رابطه بالا خنانجهـ مقــادير هو ايى مختلف برحسب تـابعى از فاصله هـوايى (g) رسـم

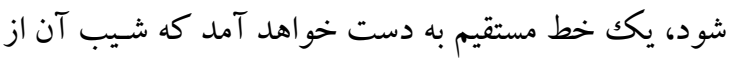
رابطه زير بهدست مى آيد:

$$
\text { slope }=\frac{1}{\operatorname{SSD}_{\text {eff }}+z_{\text {max }}}
$$

لذا، موقعيت مؤثر جشمه (SSD رابطه با بهدست آورد: 
يروتكـل AAPM TG-106 و I4) IAEA TRS-398,

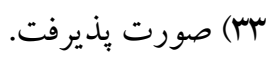

״ـس از اعتبارسـنجى مــل مونـت كـارلوى مربـوط بـه سـر

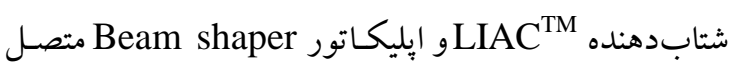
به آن، مقادير دوز جذبى در عمق دوز بيشينه به ازاى فواصل

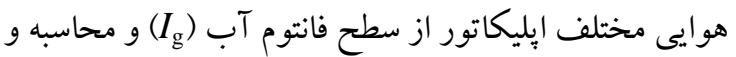
مقادير

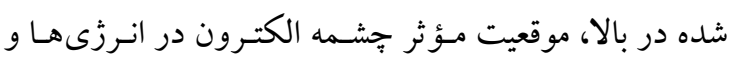

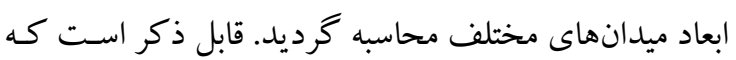
فو اصل هوايى در نظر گرفته شده (كاف هاى هو ا) ميان سطح

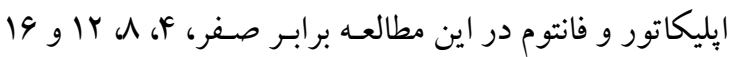
سانتى متر بود و محاسبات مربوط بـه موقعيت مـؤثر جشـمه

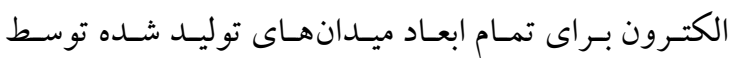
إيليكـاتور Beam shaper از كامهاى rا صورت بذيرفت. هرجند كه تعيين موقعيت مـؤثر جشـمه

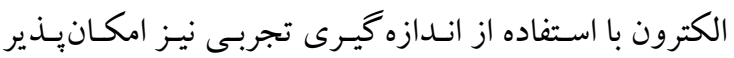
است؛ اما علت استفاده از شبيهسازى مونت كـارلو در مطالعه

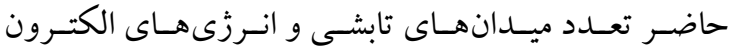
موردمطالعه بود كه باعث ايجاد بار كارى بيشازحد دستـاه در حين انجام يرتودهىهاى تجربى خواهد شد. بالينوجودو بهمنظور راستى آزمايى مقادير SSD

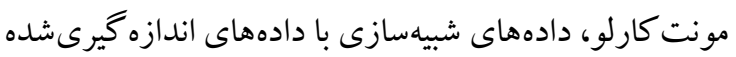

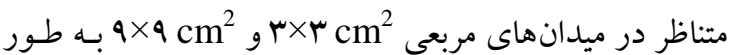
كمى مورد مقايسه قرار كرفتند.

\section{يافته ها}

منحنسى هـاى درصـد دوز عمقـى حاصـل از شـبيهسـازى

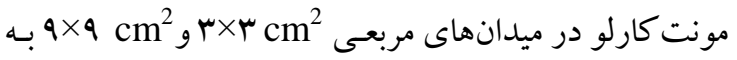

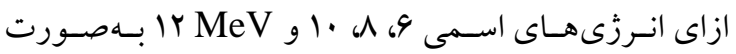

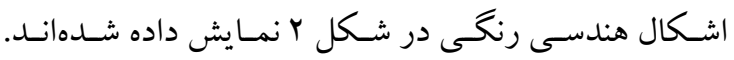

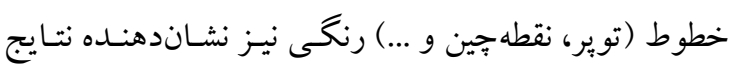

منحنى هـاى درصـد دوز عمقى حاصـل از شَبيهسـازى

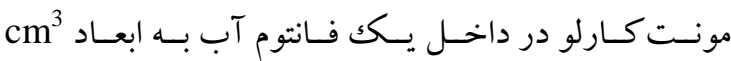

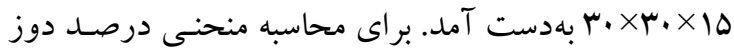
عمقى در انرزىها و ميدانهاى مختلف، ابتـدا لبـه إيليكاتور

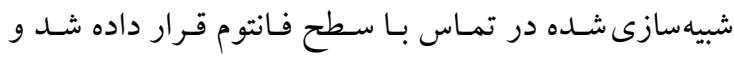
ســس منحنسى توزيـع دوز عمقسى در امتـداد محسور بـالينى

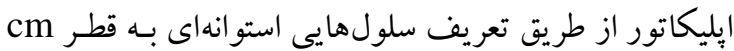

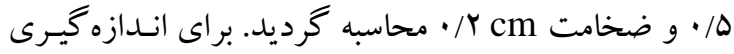
ميزان دوز جذب شده از تالى استاندارد F8* استفاده شـد. شايان ذكر است كـه تمـامى شبيهسـازىهـاى انجـامشـده از

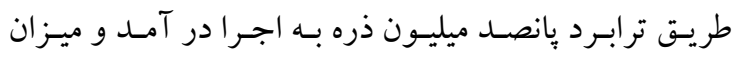

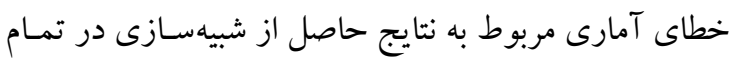

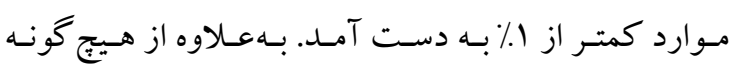
تكنيك كـاهش واريانسى در شـبيهسـازىهـاى انجـام شـده استفاده نشد. تنها به منظور كاهش زمان محاسبات، بـه دليل ترابرد هـم زمـان فوتـون و الكتـرون، از كـارت قطع انـرزى

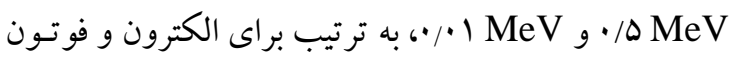

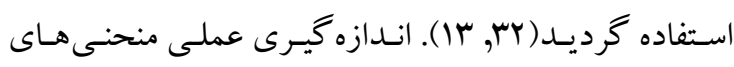
Pر داخـل يـك فـانتوم آب اتوماتيكك MPD-XS توسط بـهـــار گيرى يـك اتاقكك يـونش Markus به عنوان دوزيمتر ميدان انجام شد. در تمام اندازهگيرىها لبه إيليكاتور در تماس با سطح آب قرار داده شـد. براى كنترل حركات دوزيمتر ميدان در داخل فـانتوم آب و قرائت ياسخ آن به ترتيب از كنترل كننده TBA و الكترومتر

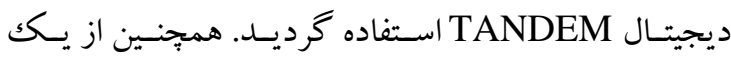
اتاقكك يونش استوانهاى Semiflex نيـز بـه عنـوان دوزيمتر

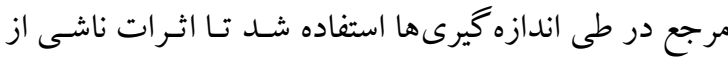

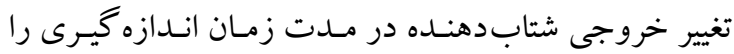

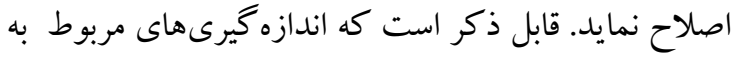

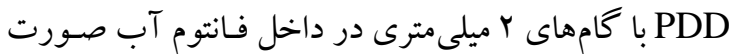

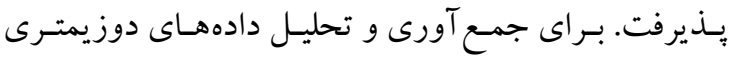

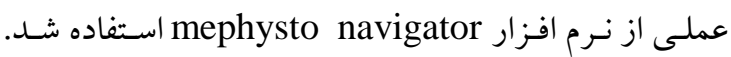

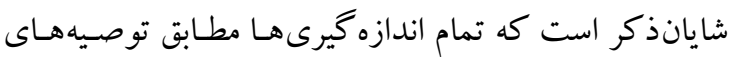


حاصل از تحليل گاما نشان مىدهـد كـه در تمـام عمتقهـاى

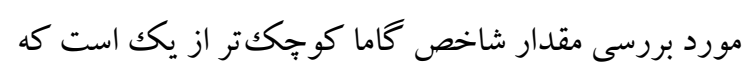

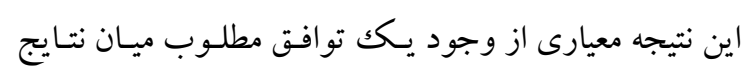
حاصل از شبيه سازى و اندازه گيرى تجربى است؛ بنسابراين بـا توجه به نتايج بـدسـت آمـده صسحت مـدل مونست كـارلوى شبيهسازى شده در اين مطالعه مورد تائيد قرار مى گيرد.

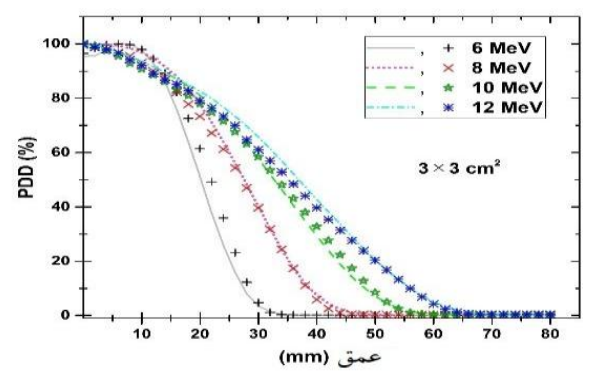

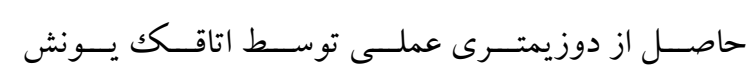
Advanced Markus دست آمده بيداست، به لحاظ كيفى توافق خوبى ميان نتايج

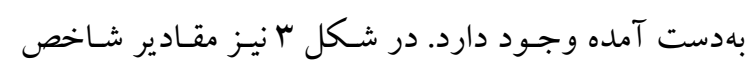

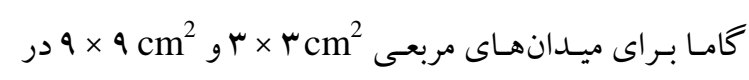

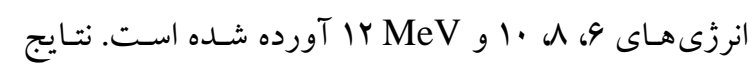

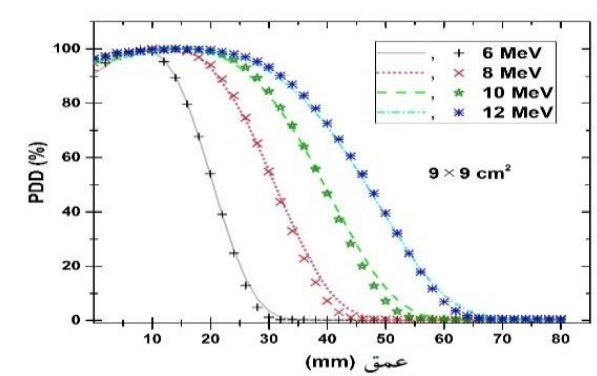

شكل r. منحنى هاى درصد دوز عمقى. نتايج حاصل از شبيهسازى مونت كارلو و اندازه تيرى عملى براى ميدانهاى مربعى

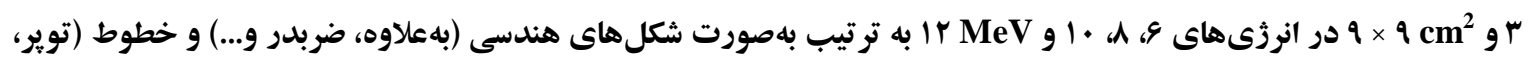
نقطه جين و ...) نمايش دادهشدهاند. بهورت
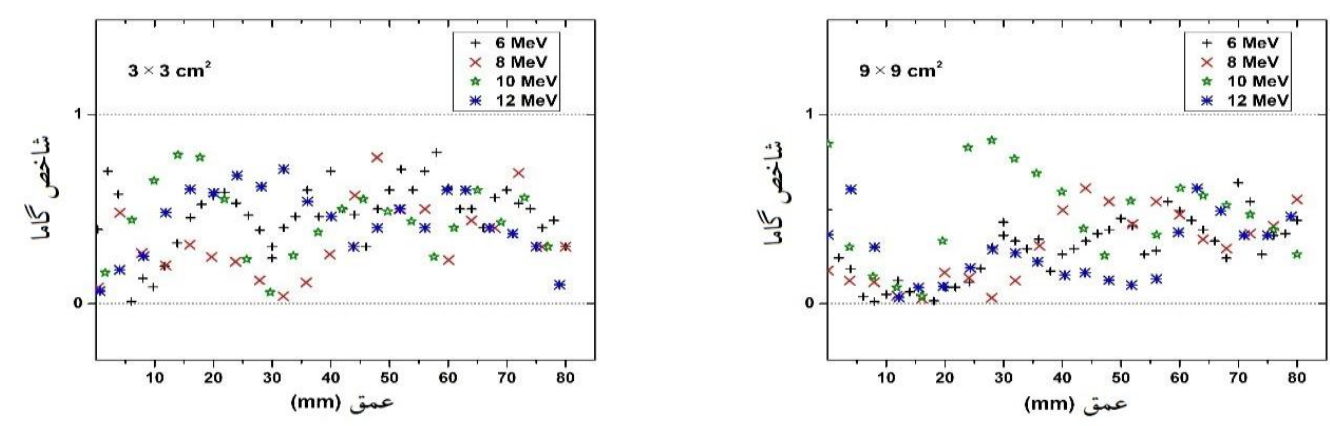

شكل r. مقادير شاخص Fاما. اين مقادير براى ميدانهاى مربعى

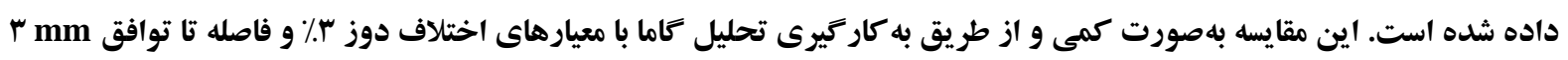

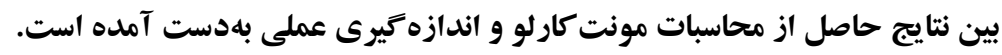

آمده است. مقادير R-Square مربوط به منحنى هـاى خطى برازش شده بر دادههاى شكل F در تمامى موارد (ميدانهاى

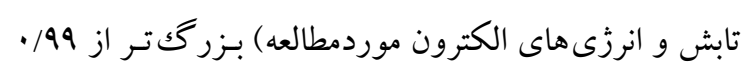
بود كه نشان از وجود يكك رابطه خطى ميان مقـادير فو اصسل هـوايى (gSD
مقادير

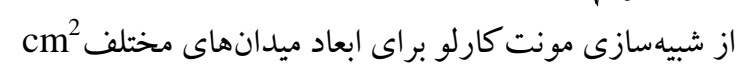

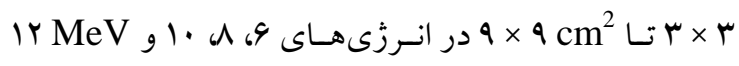
آمده. در شكل ₹ نمايش داده شده است. قابلذكر است كـه مقادير

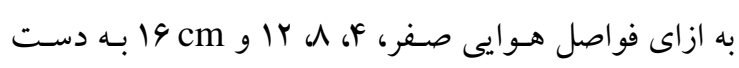



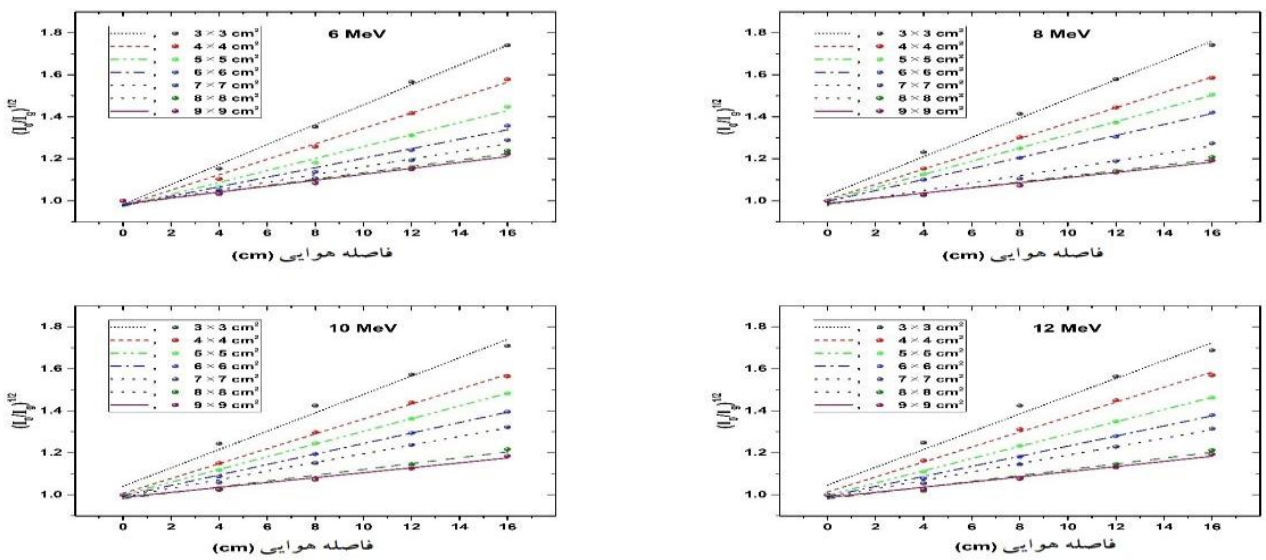

شكل ثل. مقادير

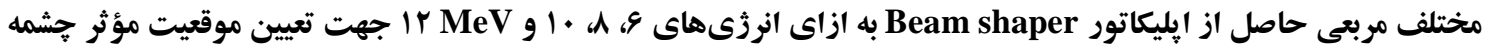
الكترون.

با تعيين شيب خطوط نشان داده در شكل f به ازاى هر ميدان و انرزى الكترون، موقعيت مؤثر جشـمه الكتـرون (SSD روش عكس مجذور فاصله (ISL) و با استفاده از رابطه (r) بهدست آمد. نتايج حاصل از محاسبه موقعيت مؤثر جشممه الكترون بـه ازاى انرزىها و ابعاد ميدان مختلف در شكل ه آورده شده است.
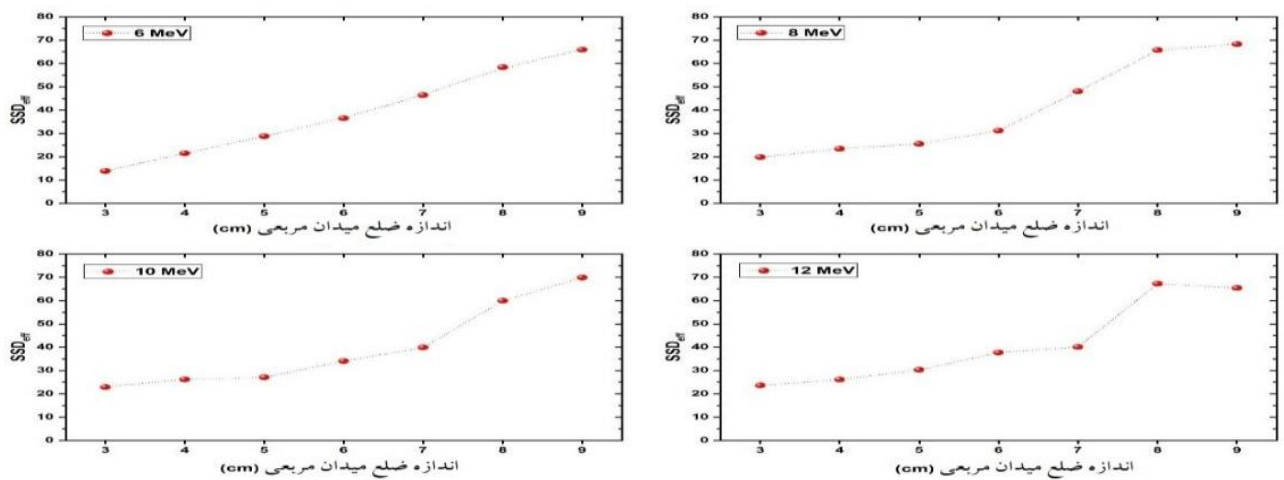

شكل ه. موقعيت مؤثر جشمه الكترون. مقادير موقعيت مؤثر جشمه الكترون (برحسب سانتىمتر ) مربوط به ميدانهاى مختلف مربعى

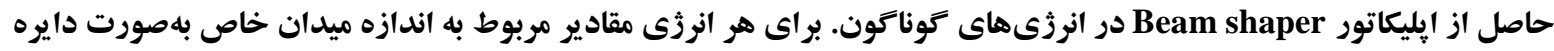

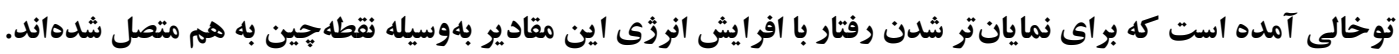

و به ازاى ميدانهاى مربعى شكل 9 نشان داده شده است.
مقايسه ميان نتايج حاصل از اندازهيرى عملى و شبيهسازى مونت كارلو در تعيين مقادير SSD 

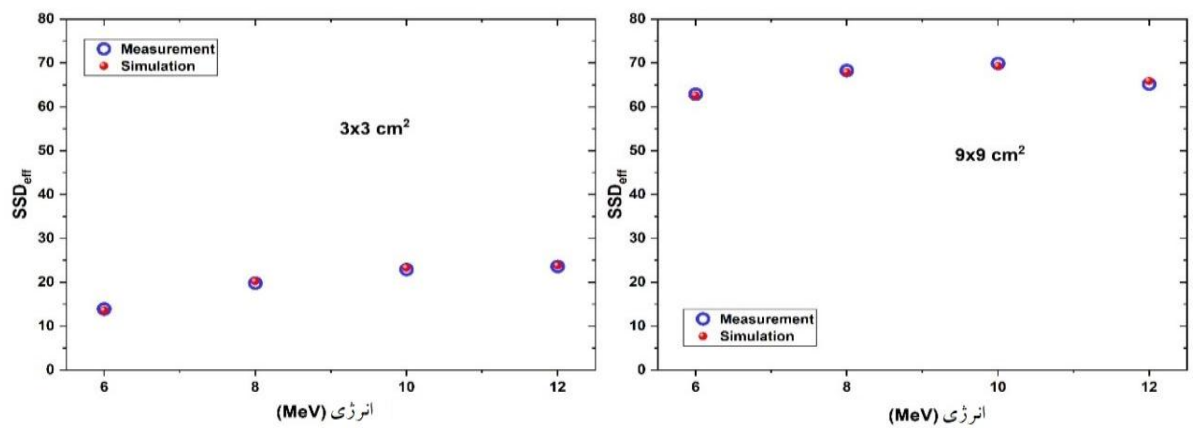

شكل צ. مقادير

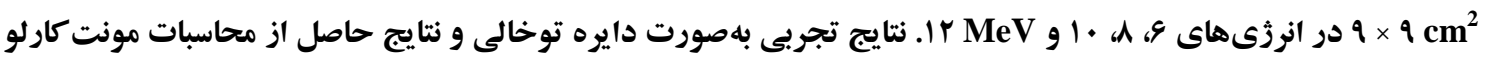
بلهورت كوى توير نمايش داده شدهاند.

نتايج بهدست آمده در شكل \& نشان مىدهـد كه بـا افزايش

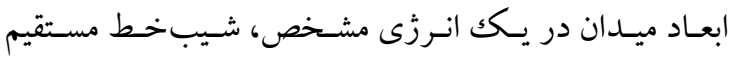

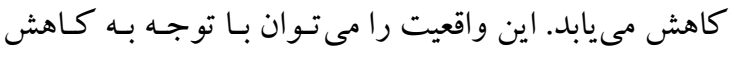
شار انرزى الكترونها بـا افزايش ابعـاد ميـدان توجيـه نمـود.

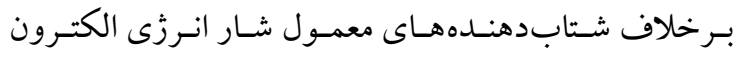
برتودرمانى حين عمل با افزايش ابعاد ميدان، به دليل سيستم

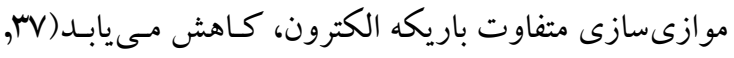
צ", 9)؛ بنابراين، با افزايش اندازه ميـدان ميزان دوز جـذبــ شده در عمق دوز بيشينه كاهش يافته (ايـن كاهش بـراى نسبت به If محسوس تر است) و ازاينرو انتظار مسرود كه.

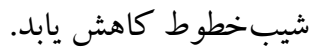

با توجه به نتايج كزارش شده شكل ه مى تـوان كفـت كه بـا افزايش ابعاد ميدان در يـك انـرزى مشـخص موقعيـت مـؤثر جشمه الكترون (SSD

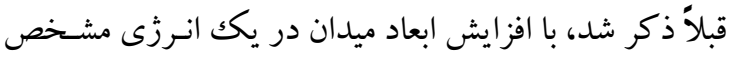
شيب خط مربوط به تغييرات

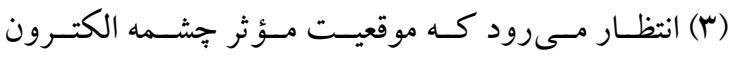

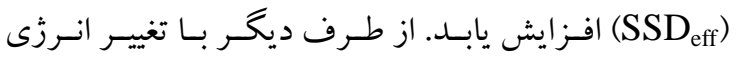

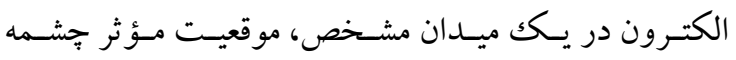
الكترون (SSD

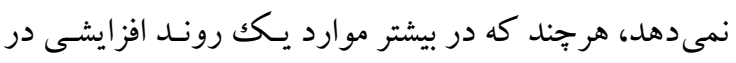

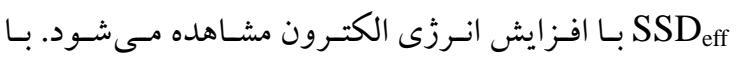

در اين يثزوهش بـه ارزيابى موقعيـت مـؤثر جشـمه الكتـرون

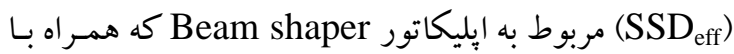

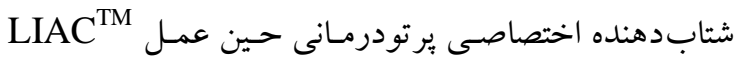
مورد استفاده قرار مى گيرد بِرداخته شد. براى اين كـار ابتـدا

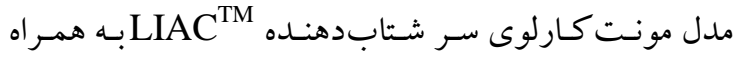
إيليكاتور Beam shaper توسط كد MCNPX شبيه سازي و پِ از اعتبارسنجى مدل توسعه يافته، موقعيت مؤثر جشمه

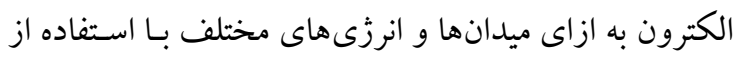
روش عكس مجذور فاصله (ISL) بهدست آمد. نتايج بهدست آمده در شكل هاى r و r صحت عملكرد مـدل

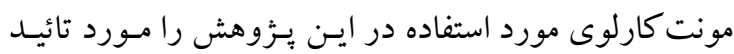

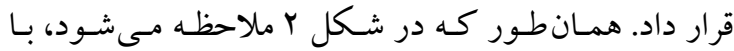
افزايش انرزى، عمق نفوذ باريكه الكترون افزايش و گرراديان

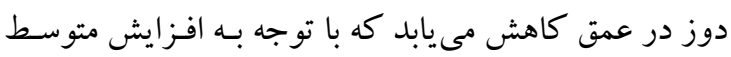

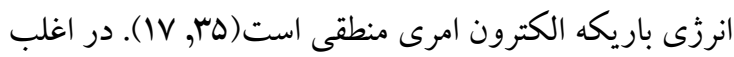

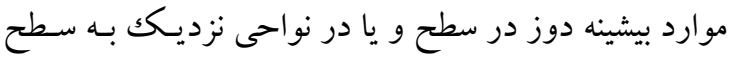

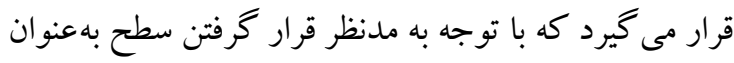

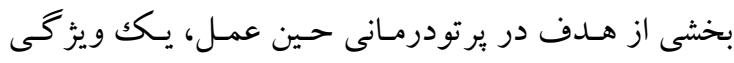
مطلوب تلقى مى گردد. بهعلاوه همانطور كه انتظار مىروده،

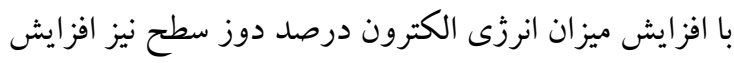

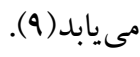




\section{نتيجه كيرى}

نتـايج بـهدسـت آمـده نشـان داد كـه موقعيـت مـؤثر باريكـهـ الكترون خـارجشـده از إيليكـاتور Beam shaper تـابعى از داز

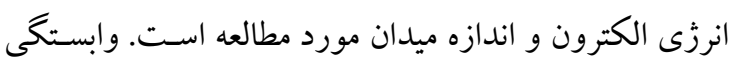
SSD به ابعاد ميدان بهمراتب بيشتر از انرزى الكترون بـود.

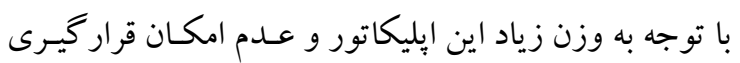
مستقيم بر روى بدن بيمـار، وجـود فاصله هـوا ميـان انتهاى

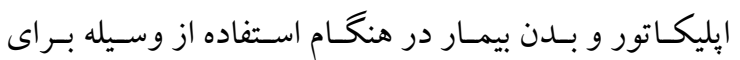
يرتودهى بيمار اجتنابنايذير خواهد بود؛ بنابراين در اختيار داشـتن مقـادير جــدولبنــى شـــه SSD در ميـدانهــاو انرزىهاى مختلف باريكه الكترون حاصل از ايـن إيليكاتور

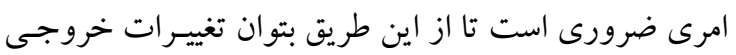

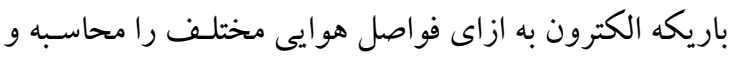
اثر آن را در محاسبات دوز بيمار و تعداد مانيتور يونيت لازم جهت تحويل ميزان دوز تجويزشده به بيمار در نظر كرفتـ

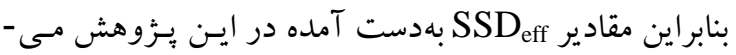
توانند در اين مقاصد بالينى مورد استفاده قرار گيرند.

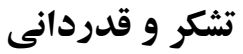

نويسـند كان مقالـه، مر اتـب قـدردانى خـود را از مســو لان و

برسنل فيزيكك بيمارستان خاتم الانبياء تهران اعلام مىدارند.

افزايش انـرزى الكتـرون در يـك ميـدان مشــص، احتمـال يراكند گى الكترون در هنگام عبور از محيط كـاهش يافته ؛

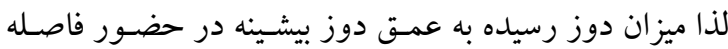

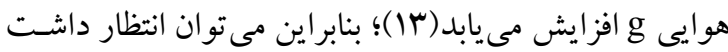
كه نسبت شيب خط راست نمايش داده شده در شكل F F كـاهش يابــ.

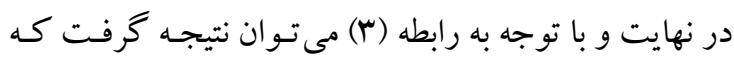
موقعيت مؤثر جشـهمه الكترون (SSD باريكه، افزايش مى يابد. با مقايسه نتايج حاصل از اندازه گيـرى تجربى و شـيهسـازى

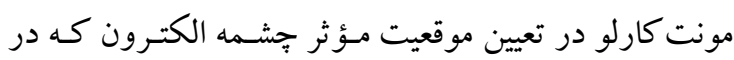
شكل 9 نمايش داده شده است، مى توان به اين نتيجه رسيد دوريد كه تو افق مطلوبى ميـان مقـادير SSD

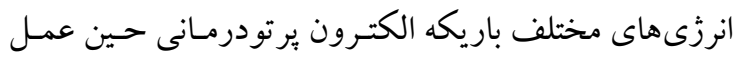

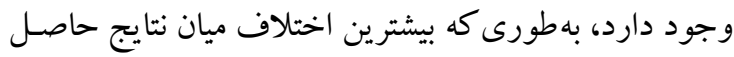

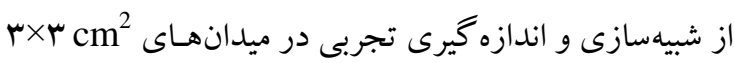

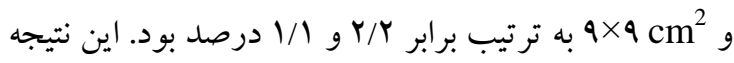
صحت مقادير SSD حاصل از شبيهسازى مونـت كـارلو را

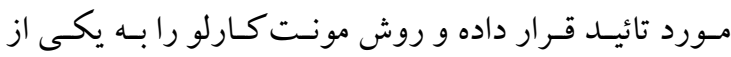
ابزارهـاى قدر تمنــــ و قابـل اعتمـاد در تعيـين موقعيـت مـؤثر

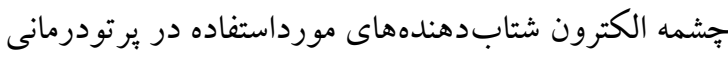

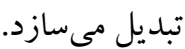

\section{منابع}

1. Willett CG, Czito BG, Tyler DS. Intraoperative radiation therapy. J Clin Oncol. 2007;25(8):971-7.

2. Harrison LB, Minsky BD, Enker WE, Mychalczak B, Guillem J, Paty PB, et al. High dose rate intraoperative radiation therapy (HDR-IORT) as part of the management strategy for locally advanced primary and recurrent rectal cancer. Int J Radiat Oncol Biol Phys. 1998;42(2):325-30.

3. Calvo F, Sole C, Herranz R, Lopez-Bote M, Pascau J, Santos A, et al. Intraoperative radiotherapy with electrons: fundamentals ,results, and innovation. Ecancermedicalscience. 2013;7:339.

4. Abe M, Takahashi M. Intraoperative radiotherapy: the Japanese experience. Int J Radiat Oncol Biol Phys. 1981;7(7):863-8.

5. Goldson AL. Preliminary Clinical Experience with lntraoperative Radiotherapy. J Natl Med Assoc. 1978;70(7):493-5.

6. Willett CG. Intraoperative radiation therapy. Int J Clin Oncol. 2001;6(5):209-14.

7. Orecchia R, Ciocca M, Tosi G, Franzetti S, Luini A, Gatti G, et al. Intraoperative electron beam 
radiotherapy (ELIOT) to the breast: a need for a quality assurance programme. Breast. 2005;14(6):541-6.

8 Heidarloo N, Baghani HR, Aghamiri SM, Mahdavi SR, Akbari ME. Commissioning of beam shaper applicator for conformal intraoperative electron radiotherapy. Appl Radiat Isot. 2017;123:69-81.

9. Baghani HR, Aghamiri SM, Mahdavi SR, Akbari ME, Mirzaei HR. Comparing the dosimetric characteristics of the electron beam from dedicated intraoperative and conventional radiotherapy accelerators. J Appl Clin Med Phys. 2015;16(2):5017.

10. Scalchi P, Ciccotelli A, Felici G, Petrucci A, Massafra R, Piazzi V, et al. Use of parallel- plate ionization chambers in reference dosimetry of NOVAC and LIAC ${ }^{\circ}$ mobile electron linear accelerators for intraoperative radiotherapy: a multi- center survey. Med Phys. 2016;44(1):321-32.

11. Baghani HR, Hosseini Aghdam SR, Robatjazi M, Mahdavi SR. Monte Carlo-based determination of radiation leakage dose around a dedicated IOERT accelerator. Radiat Environ Biophys. 2019;58:263-76.

12. Baghani HR, Robatjazi M, Mahdavi SR ,Hosseini Aghdam SR. Evaluating the performance characteristics of some ion chamber dosimeters in high dose per pulse intraoperative electron beam radiation therapy. Phys Med. 2019;58:81-9.

13. Soriani A, Iaccarino G, Felici G, Ciccotelli A, Pinnaro P, Giordano C, et al. Development and optimization of a beam shaper device for a mobile dedicated IOERT accelerator. Med Phys. 2012;39(10):6080-9.

14. Felici G, Ciccotelli A, Iacoboni V, De Angelis F, Mangiaracina N, Gava A. Device for shaping an electron beam of a machine for intraoperative radiation therapy. Google Patents; 2014.

15. Ciocca M, Pedroli G, Orecchia R, Guido A, Cattani F, Cambria R, et al. Radiation survey around a Liac mobile electron linear accelerator for intraoperative radiation therapy. J Appl Clin Med Phys. 2009;10(2):2950.

16. Hosseini Aghdam SR, Baghani HR, Mahdavi SR, Aghamiri MR, Akbari ME. Monte Carlo study on effective source to surface distance for electron beams from a mobile dedicated IORT accelerator. J Radiother Pract. 2016;16(1):29-37.

17. Khan FM, Gibbons JP. Khan's The Physics of Radiation Therapy. China: Wolters Kluwer Health; 2014.

18. Cecatti ER, Goncalves JF, Cecatti SG, da Penha Silva M. Effect of the accelerator design on the position of the effective electron source. Med Phys. 1983;10(5):683-6.

19. Righi S, Karaj E, Felici G, Di Martino F. Dosimetric characteristics of electron beams produced by two mobile accelerators, Novac7 and Liac, for intraoperative radiation therapy through Monte Carlo simulation. J Appl Clin Med Phys. 2013;14(1):3678.

20. Sordina. LIAC Technical Data Sheet. Sordina IORT Technologies. 2015.

21. Heidarloo N, Baghani HR, Aghamiri SMR, Mahdavi SR. Monte Carlo based simulation of LIAC intraoperative radiotherapy accelerator along with beam shaper applicator. IJPR. 2017;17(2):313-20.

22. Felici G. Technical Data Sheet of Beam Shaper Device. Sordina IORT Technologies. 2014.

23. Baghani HR, Heidarloo N, Aghamiri SMR, Mahdavi SR. Comparing the physical and dosimetric characteristics of cylindrical and beam shaper intraoperative radiotherapy applicators. Radiat Phys Chem. 2019;158:22-36.

24. Ravindran BP. A study on virtual source position for electron beams from a Mevatron MD linear accelerator. Phys Med Biol. 1999;44(5):1309-15.

25. Meyer JA, Palta JR,Hogstrom KR. Demonstration of relatively new electron dosimetry measurement techniques on the Mevatron 80. Med Phys. 1984;11(5):670-7.

26. Jamshidi A, Kuchnir FT, Reft CS. Determination of the source position for the electron beams

هبلم علدى دانشكاه علوه بِزشكى كردستان / دوره بيست و شش / دعر و آبان م.ع|| 
from a high-energy linear accelerator. Med Phys. 1986;13(6):942-8.

27. Khan FM, Sewchand W, Levitt SH. Effect of air space and depth dose in electron beam therapy. Radiology. 1978;126(1):249-51.

28. Podgorsak EB. Review of radiation oncology physics: a handbook for teachers and students. Vienna, International Atomic Energy Agency Educational reports series. 2003.

29. Hendricks JS, McKinney GW, Fensin ML, James MR, Johns RC, Durkee JW, et al. MCNPX 2.6. 0 Extensions. Los Alamos National Laboratory, LA-UR-08-2216. 2008.

30. Low DA, Dempsey JF. Evaluation of the gamma dose distribution comparison method. Med Phys. 2003;30(9):2455-64.

31. Low DA, Harms WB, Mutic S, Purdy JA. A technique for the quantitative evaluation of dose distributions. Med Phys. 1998;25(5):656-61.

32. Iaccarino G, Strigari L, D'Andrea M, Bellesi L, Felici G, Ciccotelli A, et al. Monte Carlo simulation of electron beams generated by a $12 \mathrm{MeV}$ dedicated mobile IORT accelerator. Phys Med Biol. 2011;56(14):4579-96.

33. Das IJ, Cheng CW, Watts RJ, Ahnesjo A, Gibbons J, Li XA, et al. Accelerator beam data commissioning equipment and procedures: report of the TG-106 of the Therapy Physics Committee of the AAPM. Med Phys. 2008;35(9):4186-215.

34. IAEA. Absorbed dose determination in external beam radiotherapy: An international code of practice for dosimetry based on standards of absorbed dose to water. TRS 398. 2000.

35. Chang D, Lasley F, Das I, Mendonca M, Dynlacht J. Dosimetry of Photon Beams in Water. Basic Radiotherapy Physics and Biology: Springer International Publishing; 2014. 77-92.

36. Pimpinella M, Mihailescu D, Guerra AS, Laitano RF. Dosimetric characteristics of electron beams produced by a mobile accelerator for IORT. Phys Med Biol. 2007;52(20):6197-214.

37. Heidarloo N, Baghani HR, Aghamiri MR, Mahdavi sR. Evaluating the Photon Contamination of Beam Shaper Applicator Using Monte Carlo Simulation. JMUMS. 2016;26(140):212-7. 